\title{
A transmissão intergeracional de conhecimento e o habitus
}

Glauber Brito Matos Lacerda

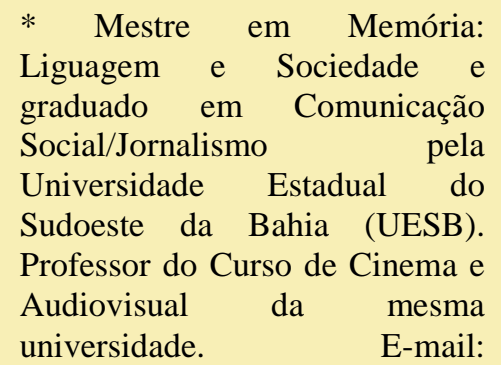

Social/Jornalismo

Universidade Estadual do

Sudoeste da Bahia (UESB).

Professor do Curso de Cinema e

Audiovisual da mesma

universidade.

E-mail:

glaubml@gmail.com.

Resumo: O presente artigo estuda a relação existente entre transmissão intergeracional de conhecimento, conforme Norbert Elias a trata em Teoria Simbólica, e a incorporação deste em forma habitus, tomando de empréstimo o modo como Bourdieu trabalha esta categoria.

Palavras-chave: Habitus, Teoria Simbólica, Conhecimento.
Abstract: This paper studies the relationship between the intergenerational transmission of knowledge, according to Norbert Elias defines Symbolic Theory, and the incorporation of knowledge in habitus, as Bourdieu conceptualizes this category.

Keywords: Habitus, Symbolic Theory, Knowledge. 
Partindo da praxiologia de Pierre Bourdieu e da sociologia configuracional de Norbert Elias, aproximaremos a noção de habitus, ao modo que Bourdieu a trata, e a teoria simbólica eliasiana para compreender como os indivíduos incorporam saberes e fazeres plasmados em bens culturais que atravessam gerações. Ambos os autores pensam uma sociologia em que as estruturas objetivas e subjetivas se encontram em jogo, não polarizadas; consequentemente, eles se valem do pressuposto que o indivíduo tem uma propensão plástica de continuação da formação do autocontrole por aprendizado que favorece a incorporação do saber simbolicamente elaborado. Em linhas gerais, essa capacidade humana é o que se chama de habitus. Por outro lado, precisamos considerar que os indivíduos nascem em sociedades peculiares. O habitus, assim, constitui-se a partir de bens culturais, precedentes ao indivíduo, em contínuo processo de transformação e com a capacidade de transmitir conhecimento numa perspectiva intergeracional.

Abaixo, discutiremos a transmissão intergeracional de conhecimento e incorporação desses bens culturais pelos indivíduos, proporcionando o autocontrole dos mesmos na vida social. Para tanto, faremos uma incursão na teoria simbólica de Norbert Elias, a fim de apreender como o conhecimento é transmitido entre gerações, plasmado

Dossiê Cinema e Audiovisual: entre o sensível e o reflexivo

Arquivos do CMD, Volume 3, N. 1. Jan/Jul 2015 nos usos das línguas. Em seguida, valeremo-nos da conceituação de habitus, de Bourdieu, para entender como o indivíduo incorpora estes bens que regulam as formas de saber, ser e perceber.

O presente artigo corresponde à parte da discussão teórica da dissertação Der Leone Have Sept Cabeças: imagens da memória no cinema de Glauber Rocha, que investiga como o conhecimento recebido e incorporado pelo artista numa dada configuração social está presente no seu filme. Não iremos nos deter em nenhuma análise do corpus, pois extrapolaria os limites desta publicação. Optamos por fazer uma discussão teórica que dê conta de parte da ferramenta analítica que construímos para analisar o objeto.

\section{Transmissão intergeracional de conhecimento}

No livro Teoria Simbólica, Norbert Elias propõe uma reformulação das teorias do conhecimento vigentes, hegemonicamente individualistas, em prol de uma abordagem que pense a construção do conhecimento como coletiva e intergeracional. Para empreender tal reflexão, o sociólogo se volta para a natureza das línguas humanas e 
demonstra como esses sistemas de representação simbólica acumulam conhecimento e dão coesão a grupos sociais. Para Elias (2002, p.4):

[...] Com o auxílio de uma ampla gama de padrões sonoros [...], os seres humanos têm a capacidade de comunicar entre si. Eles podem armazenar conhecimento na sua memória e transmiti-lo de uma geração para outra. Uma forma muito definida de estandardização social permite que, no interior de uma mesma sociedade, os mesmos padrões sonoros sejam reconhecidos por todos os membros mais ou menos com mesmo sentido, ou seja, como símbolos que representam o mesmo tipo de conhecimento.

Portanto, a comunicação humana é um legado das padronizações sonoras. Só se pode falar das coisas existentes porque há palavras que as representem. Os seres humanos têm em comum com outras espécies a capacidade de comunicar através de som. Contudo, cada sociedade tem seus padrões sonoros próprios. O aspecto biológico, isto é, a capacidade de aprender padrões sonoros de uma sociedade específica, encontra-se em paralelo com os aspectos culturais, pois, na medida em que os corpos possuem a faculdade de aprender e transmitir um vasto leque de padrões sonoros, os grupos humanos se mantêm coesos e, na medida em que novas palavras são criadas para nomear novas descobertas, deposita-se mais conhecimento na língua. Assim, o conhecimento é um fluxo contínuo. Essa lógica colide com o modelo individualista da filosofia europeia que pensa o homem como sujeito do conhecimento. Elias acusa o transcendentalismo kantiano como um dos responsáveis por essa concepção.

Kant afirma que a explicação através da relação causa/efeito é um $a$ priori da razão humana. Para Elias (2002, p. 9-10), Kant não explica questões que fogem das "propriedades" que "moldam" a razão humana:

[...] Como uma forma de orientação, o raciocínio humano, segundo Kant, tinha limites definidos. Somos compelidos a adequar as nossas experiências a um padrão predeterminado ditado pela natureza humana. A força constrangedora da expectativa de encontrar soluções para todos os tipos de problema sob a forma de uma relação de causa-efeito pode servir de exemplo. Ela não provém da natureza dos objectos do raciocínio, mas sim da natureza dos sujeitos.

Se o pensamento kantiano estivesse voltado para a natureza do objeto, como sugere Elias, e não dos sujeitos, ele teria se questionado como se deu a aprendizagem intergeracional do termo "causa". A 
causalidade é produto de como o padrão sonoro "causa" vem sendo ressignificado de geração em geração. Assim, não podemos compreender o conhecimento como sendo próprio dos indivíduos, mas da relação destes com a teia social em que estão inseridos. A língua, mais uma vez, pode ser notada como agregadora de conhecimento. Ela só existe no nível extraindividual, pois só pode se efetivar como língua quando mais de uma pessoa a compreende.

Norbert Elias propõe na Teoria Simbólica uma reflexão sobre o conhecimento que tenha como um dos aspectos basilares um diálogo com as ciências biológicas. Ao contrário das ciências sociais, os recortes de tempo da biologia são muito mais extensos. Os cientistas dedicados ao estudo das espécies não se detêm a compreender a evolução delas no decorrer de séculos, mas sim em milhares de anos. A teoria eliasiana, portanto, defende que o processo de acúmulo de fundos simbólicos da humanidade não se compreende em períodos curtos.

Elias faz uma distinção entre "evolução" e "desenvolvimento", processos que dizem respeito, respectivamente, às transformações biológicas e culturais. Durante um longo período de tempo, que não se sabe ao certo quanto, o homem evoluiu até chegar a um estágio capaz de apreender padrões sonoros em forma de uma língua. Todavia, essas línguas continuam se desenvolvendo, incorporando novas palavras Dossiê Cinema e Audiovisual: entre o sensível e o reflexivo Arquivos do CMD, Volume 3, N. 1. Jan/Jul 2015 correspondentes a novas descobertas. E, ao que parece, a capacidade de desenvolvimento das culturas humanas é infinita. Portanto, ao buscar uma análise de longo prazo, Elias evita dois erros comuns no modelo de homem hegemônico nos estudos das sociedades. Primeiro, o homem é uma espécie diferente das outras, pois além de evoluir, ele também dispõe da faculdade para se desenvolver. Segundo, quando se pensa que os aspectos constitutivos do homem têm sua origem no processo milenar de evolução da espécie, as idiossincrasias humanas deixam de ser atribuídas a uma essência, ou seja, a alma, o que seria uma concepção atemporal. O modelo humano eliasiano é historicizado, não se calca no dualismo corpo e alma.

Para entender melhor as diferenças entre os sons pré-verbais e os sons produzidos na vida cultural, podemos comparar os padrões sonoros dos animais com os padrões sonoros humanos. Elias (2002, p.40) elenca três peculiaridades que distinguem os sons emitidos pelos homens: “(a) têm de ser adquiridos através da aprendizagem; (b) podem variar de uma sociedade para outra; e (c) podem variar no tempo e no interior de uma mesma sociedade". Ao mesmo tempo, a fala localiza o ser falante no tempo e no espaço, os pronomes pessoais e as flexões verbais distanciam o homem daquilo do que ele fala, podendo ele se referir a outrem ou outra coisa qualquer no passado, no presente ou no futuro. Já os sons 
emitidos por outros animais apenas denunciam a condição do indivíduo no presente. Logo, o gemido de um cão é um sinal de uma dor que o macula no exato instante em que chora, diferente de um lamento humano que pode se referir a uma mágoa devido a algo que aconteceu em um momento distinto. Desta maneira, ao adquirir, no decorrer de sua evolução biológica, a capacidade de aprender uma língua, os seres humanos passaram a ter duas vantagens em relação aos outros animais: $1^{\circ}$ ) os grupos humanos se tornaram mais coesos; $2^{\circ}$ ) a comunicação verbal é mais precisa na mensagem, ela é mais flexível de acordo a situações diferentes. Trata-se de uma evidência que natureza e cultura não são aspectos isolados entre si na constituição do homem.

A língua é simbólica porque precisa ser aprendida. As coisas só podem ser reconhecidas pelo grupo se houver um correspondente simbólico, palavras que as definem. A espécie humana, ao evoluir e desenvolver a capacidade de aprender padrões sonoros, conquistou sua "emancipação simbólica" (ELIAS, 2002, p. 55). Mas tal faculdade é permeada por jogos de poder. Não é à toa que, num dado contexto social, prevaleçam elocuções mais aceitáveis, tidas como "corretas" em relação a outras. Elias (2002, p. 51) constata que, nessa teia de tensões em que se encontram os usuários de um idioma, um ato individual nunca

Dossiê Cinema e Audiovisual: entre o sensível e o reflexivo

Arquivos do CMD, Volume 3, N. 1. Jan/Jul 2015 se produz isoladamente, está sempre relacionado com a configuração societal:

[...] Podemos evocar a ênfase que Max Weber colocou no significado que uma acção apresenta para o actor individual. Porém, uma acção individual raramente é auto-suficiente. É, habitualmente, orientada para as acções de outras pessoas. Em geral, o significado de uma acção para o actor é codeterminada pelo significado que ela assume para outros. As relações das pessoas entre si não são aditivas. A sociedade não é um amontoado de acções individuais comparável a um monte de areia, nem é um formigueiro de indivíduos programados no sentido de uma cooperação mecânica. Ela assemelhase antes a uma teia de pessoas vivas que, sob uma diversidade de formas, são interdependentes.

Diante da teia social em que os indivíduos nascem, torna-se imprescindível que os bebês aprendam uma língua para se tornarem "seres humanos plenamente desenvolvidos" (ELIAS, 2002, p. 53). Logo, à luz do pensamento eliasiano, constatamos, mais uma vez, a incompatibilidade com o modelo individualista das teorias do conhecimento. Não existe a possibilidade de o indivíduo adquirir conhecimento se ele se desenvolve isolado de outros humanos, de uma língua, o que faz Elias afirmar que conhecimento, linguagem e 
pensamento não são atributos isolados no ser humano. É através da linguagem que a transmissão intergeracional de conhecimento acontece, ao passo que existe uma via de mão dupla entre o pensamento e a linguagem: a linguagem fomenta o pensamento ao mesmo tempo em que o pensamento atualiza a linguagem criando novos conceitos, isto é, conhecimento que é também linguagem. Em outras palavras, Elias (2002, p. 72) atribui ao conhecimento, à linguagem e ao pensamento, respectivamente, as funções de "orientação", "comunicação" e "exploração" no universo simbólico das sociedades humanas. É importante frisar que as três atividades dizem respeito "à manipulação de imagens aprendidas e armazenadas na memória”. Tal interligação só é observável se sairmos do individualismo de determinadas teorias para pensar o conhecimento como uma construção social.

Mas, afinal, o que são as coisas que não existem e mesmo assim os homens as nomeiam? O que são os símbolos da fantasia? São irracionais, portanto distintos do intelecto? Numa perspectiva teórica que pensa o conhecimento como o mero acumulado dos resultados científicos, pode-se levar em consideração que a fantasia é contrária ao intelecto. Contudo, Elias pensa não só no conhecimento científico, mas também no conhecimento que atravessa a vida prática e cotidiana das sociedades. Por essa perspectiva, a fantasia não apenas é “o pai e mãe da Dossiê Cinema e Audiovisual: entre o sensível e o reflexivo Arquivos do CMD, Volume 3, N. 1. Jan/Jul 2015 arte" (ELIAS, 2002, p. 73), pois é tributária a ela a sobrevivência da humanidade. Se não fossem os mitos que muitas vezes orientaram e orientam os homens a fazerem ou não fazerem determinadas coisas, a humanidade teria ruído. Partindo deste pressuposto, Elias abandona o dualismo verdadeiro/falso para valorar o conhecimento e propõe se pensar em conhecimento mais ou menos "coerente com a realidade". A Teoria Simbólica, por exemplo, é uma tentativa do sociólogo em fazer uma teoria do conhecimento mais coerente com a realidade do que as existentes no momento em que a formulava.

Antes de adentrarmos à discussão sobre habitus para compreendermos melhor como se dá a incorporação pelo indivíduo do conhecimento existente nas teias sociais, plasmado em bens culturais como a língua, é importante destacar o legado de Elias em sua teoria ao atribuir uma dimensão simbólica ao mundo que, somada às quatro outras já reconhecidas pelas ciências (as três espaciais e o tempo), concebe a realidade como "penta-dimensional” (ELIAS, 2002, p.127).

\section{Os usos linguísticos e o habitus}


Assim como Elias, Pierre Bourdieu parte do pressuposto de que a linguagem não pode ser entendida por si só. O poder das palavras, ao contrário do que pensou Ferdinand Saussure, é indissociável dos usos que se fazem delas na vida social:

[...] Tentar compreender linguisticamente o poder das manifestações lingüísticas ou, então, buscar na linguagem o princípio da lógica e da eficácia da linguagem institucional, é esquecer que a autoridade que reveste a palavra vem de fora (BOURDIEU, 1996, p. 87).

Para empreender o estudo acerca dos usos linguísticos, Bourdieu toma como objeto os "rituais de magia social", ritos instituídos dentro do tecido social com o poder "mágico" de instituir. A "magia social" permeia os atos de autoridade cujo êxito está subordinado às condições sociais que sustenta os ritos sociais. Os discursos de autoridade (os sermões, as sentenças) podem não ser entendidos, porém devem ser compreendidos. As pessoas podem não saber ao certo o que as autoridades dizem, mas sabem qual a finalidade do discurso, o que causa um sentido social, mostrando como os ritos são miraculosos. O poder dos atos de autoridade são maiores ou menores ao depender de quem fala, de que lugar fala e o que fala.

Bourdieu foca sua análise nas características comuns dos "ritos de instituição". O sociólogo cunha este termo como alternativa a "ritos de passagem". O novo conceito é mais adequado porque o mais importante nesses eventos sociais não são os processos pelos quais os indivíduos passam no transcurso da vida para mudar de uma condição social para outra, mas sim a linha tênue que separa aqueles que são daqueles que não são ainda, e, magicamente, consagra novos estados para os indivíduos. Os ritos de instituição são miraculosos a partir do momento em que fazem um limite arbitrário parecer natural. Portanto, instituir, para Bourdieu, é consagrar. São os rituais de instituição que fomentam a essência social e, por intermédio da atribuição estatutária, a legitimação dos atos de autoridade se faz mais potente:

[...] aquele que é instituído sente-se intimado a ser conforme à sua definição, à altura de sua função. [...] Os sociólogos da ciência chegaram à conclusão de que as maiores realizações científicas eram de autoria de pesquisadores egressos das instituições escolares de maior prestígio. Tal fato se explica em ampla medida pela elevação do nível de aspirações subjetivas que determinam o reconhecimento coletivo (isto do nível de aspirações subjetivas que 
determinam o reconhecimento coletivo (isto é, objetivo) destas aspirações e a atribuição a uma classe de agentes (os homens, os alunos das grandes escolas, os escritores consagrados etc.) aos quais não apenas tais aspirações são concedidas e reconhecidas como direitos ou privilégios (em oposição às pretensões pretensiosas dos pretendentes), mas também atribuídas, impostas, enquanto deveres, mediante reforços, encorajamentos e incessantes apelos à ordem (BOURDIEU, 1996, p. 101).

Bourdieu constata que a herança - todo arcabouço simbólico que permeia os grupos sociais, consagrado pelos ritos de instituição - herda o herdeiro, tendo em vista que o indivíduo é um mantenedor de práticas sociais incorporadas no habitus. É o que motiva, por exemplo, as renúncias próprias às classes aristocráticas, o autocontrole em relação aos desejos, para melhor manter os privilégios. Diante das tentações de se integrar a tendências contraculturais, os aristocratas tendem a se esforçar para manter os valores ditos culturais. Essa disposição é transmitida intergeracionalmente para que as gerações vindouras mantenham os privilégios. Assim, os signos incorporados são latentes (o sotaque, as pronuncias, as maneiras de falar, o vocabulário, os jeitos de corpo, entre outros) e estão, a todo o momento, lembrando o indivíduo da sua "essência social". Aqueles que possuem uma essência social privilegiada ainda podem se dar ao luxo de afirmar que têm gostos Dossiê Cinema e Audiovisual: entre o sensível e o reflexivo Arquivos do CMD, Volume 3, N. 1. Jan/Jul 2015 "duvidosos", o que jamais é permitido para os pequenos burgueses que estão sujeitos a uma constante autocorreção.

Em conformidade com pensamento eliasiano, Bourdieu parte da premissa que o corpo humano tem a capacidade de incorporar conhecimento, razão que o faz, ao mesmo tempo, social e individual. Destarte, o habitus porta as capacidades incorporadas de “coletivização". Bourdieu (2001, p. 163) evoca Hegel para corroborar com o entendimento de habitus:

[...] como diz Hegel: tendo a propriedade biológica de estar aberto e exposto ao mundo, suscetível de ser por ele condicionado, moldado pelas condições materiais e culturais de existência nas quais ele está colocado desde a origem, o corpo está sujeito a um processo de socialização cujo produto é a própria individualização, a singularidade do "eu" sendo forjada nas e pelas relações sociais.

Se o "eu" é fruto das relações sociais, supõe-se que os indivíduos nunca estão sozinhos, pois mesmo na ausência de terceiros num mesmo espaço físico, há um espaço social que mantém uma troca constante e invisível entre os agentes. O espaço social se estrutura pelo conjunto de posições sociais justapostas, isto é, pela distribuição de diferentes 
capitais no tecido social. Já o espaço físico é uma espécie de tradução imperfeita do seu equivalente social: "O espaço social tende a se retraduzir, de maneira mais ou menos deformada, no espaço físico, sob a forma de um certo arranjo de agentes e propriedades" (BOURDIEU, 2001, p.164). A relação do corpo é diferente em cada uma das categorias de espaço. No físico, o indivíduo tem uma relação direta com o mundo. Já no social, o agente está ligado a um campo, em que a illusio - a força que o campo exerce sobre seus participantes - faz com que o agente seja afetado sem que haja contatos físicos, apenas trocas simbólicas.

O habitus, assim como a teoria simbólica eliasiana, não pode ser compreendido através do modelo individualista de homem. É o “[...] corpo socializado, investindo na prática dos princípios organizadores socialmente construídos e adquiridos no curso de uma experiência social situada e datada" (BOURDIEU, 2001, p. 167). A noção de habitus serve para corrigir dois erros presentes na sociologia: $1^{\circ}$ ) a ideia herdada da mecânica newtoniana de que para cada estímulo externo o corpo tem reação específica; $2^{\circ}$ ) estando os indivíduos prenhes de uma construção social, eles nunca agem de forma completamente consciente, como comumente se pensa. Assim
[...] Contra ambas as teorias, convém ressaltar que os agentes sociais são dotados de habitus, inscritos nos corpos pelas experiências passadas: tais sistemas de esquemas de percepção, apreciação e ação permitem tanto operar atos de conhecimento prático, fundados no mapeamento e no reconhecimento de estímulos condicionais e convencionais a que os agentes estão dispostos a reagir, como também engendrar, sem posição explícita de finalidades nem cálculo racional de meios, estratégias adaptadas e incessantemente renovadas, situadas porém nos limites das constrições estruturais de que são o produto a que as definem (Bourdieu, 2001, p. 169)

É importante destacar que os atos práticos dos indivíduos não são pensados, calculistas, egoístas, conforme pensa os "individualistas metodológicos". As maneiras de ser, pensar e agir partem, muitas vezes, de uma espontaneidade própria dos elementos sociais incorporados. Concomitantemente, o habitus engendra "solidariedades duráveis", como no caso dos sacrifícios das aristocracias para manter os privilégios que tratamos acima. A aprendizagem através do corpo é, sobretudo, afetiva. Então, não é apenas pelas normatizações que os indivíduos se adequam à convivência social. As pequenas situações ordinárias também oprimem e pressionam o indivíduo a se adequar à vida prática, criando 
as disposições do habitus, embora estas só se expressem quando a posição social do agente é favorável. Todavia, o habitus pode criar as situações favoráveis para se expressar:

O habitus como sistema de disposições de ser e de fazer constitui uma potencialidade, um desejo de ser que, de certo modo, busca criar as condições de sua realização, portanto a impor as condições de sua realização, portanto a impor as condiç̃es mais favoráveis ao que ele é (BOURDIEU, 2001, p.182).

A possibilidade de o habitus criar meios para se potencializar não significa que o indivíduo tenha autonomia para se satisfazer no seu meio social. O grau de satisfação do agente depende muito mais das condições oferecidas pelo campo.

O habitus é uma noção relacionada com a história. Devemos levar em consideração como se relaciona a "história tornada coisa", os padrões sonoros, como diria Elias, que, nos processos históricos, significam/ressignificam os objetos, e a "história tornada corpo", o próprio habitus. Conforme exemplifica Bourdieu (2001, p. 184):
O habitus, produto de uma aquisição histórica, é o que permite a apropriação do legado histórico. Assim como a letra só deixa de ser letra morta pelo ato de leitura que supõe uma aptidão adquirida para ler e decifrar, a história objetivada (nos instrumentos, monumentos, obras, técnicas etc.) somente consegue converter-se em história atuada e atuante quando é assumida por agentes que, por conta de seus investimentos anteriores, se mostram inclinados a se interessar por ela e dotados das aptidões necessárias para reativá-las.

Neste ponto, há um cruzamento crucial entre o pensamento de Elias e o de Bourdieu. O primeiro afirma que para se comunicar sobre a existência dos objetos, sejam os mais corriqueiros, necessita-se de símbolos que os represente:

[...] Os objectos mais vulgares da nossa vida quotidiana como os botões, as camisas, as escadas e as bicicletas necessitam de uma representação simbólica padronizada como condição para podermos comunicar sobre eles (ELIAS, 2002, p.5)

Os indivíduos só entendem a existência das coisas se o seu habitus for condicionado a isso no transcurso da história individual através dos processos de aprendizagem que só são possíveis nas relações sociais. 


\section{Conclusão}

No percurso que seguimos no presente artigo, notamos que a língua, ou melhor, os padrões sonoros de uma sociedade, é uma peça indispensável para compreendermos a transmissão intergeracional de conhecimento e a incorporação dos mesmos através do habitus. Enquanto Elias pensa a língua como depositária de conhecimento, Bourdieu elabora um pensamento para compreender como esse bem cultural é utilizado na sociedade e, através de alguns mecanismos "mágicos" (como os ritos de instituição), as palavras ganham sentidos que os indivíduos incorporam, ao ponto de influenciar não apenas sua fala, mas suas ações, pensamentos e preferências.

\section{Referências}

BOURDIEU, Pierre. A Economia das Trocas Lingüísticas - o que falar quer dizer. $1^{\text {a }}$ Ed. São Paulo, Edusp, 1996.

BOURDIEU, Pierre. Meditações Pascalianas. $1^{\mathrm{a}}$ Ed. Rio de Janeiro, Bertrand Brasil, 2001.

ELIAS, Norbert. Teoria Simbólica. $2^{\mathrm{a}}$ Ed. Oeiras, Celta Editora, 2002.

Dossiê Cinema e Audiovisual: entre o sensível e o reflexivo

Arquivos do CMD, Volume 3, N. 1. Jan/Jul 2015 